\title{
Delirium og kognitiv svikt blant eldre i norske akuttmottak
}

ORIGINALARTIKKEL

\section{SIGURD EVENSEN}

E-post: sigurd.evensen@ntnu.no

Diakonhjemmet Sykehus

og

Institutt for nevromedisin og bevegelsesvitenskap

NTNU

Han har bidratt med ideen til prosjektet, prosjektplanlegging, datainnsamling (St. Olavs hospital), primær utarbeiding av manus og har godkjent den siste manusversjonen.

Sigurd Evensen er spesialist i geriatri, overlege og stipendiat.

Forfatter har fylt ut ICMJE-skjemaet og oppgir ingen interessekonflikter.

\section{INGVILD SALTVEDT}

Avdeling for geriatri

St. Olavs hospital

og

Institutt for nevromedisin og bevegelsesvitenskap

NTNU

Hun har bidratt med prosjektansvar, prosjektplanlegging, utarbeiding av manus og har godkjent den siste manusversjonen.

Ingvild Saltvedt er spesialist i geriatri, avdelingssjef og professor.

Forfatter har fylt ut ICMJE-skjemaet og oppgir ingen interessekonflikter.

\section{ANETTE HYLEN RANHOFF}

Medisinsk avdeling

Diakonhjemmet Sykehus

og

Klinisk institutt 2

Universitetet i Bergen

Hun har bidratt med prosjektplanlegging, datainnsamling (Diakonhjemmet Sykehus), utarbeiding av manus og har godkjent den siste manusversjonen.

Anette Hylen Ranhoff er spesialist i geriatri, overlege og professor.

Forfatter har fylt ut ICMJE-skjemaet og oppgir ingen interessekonflikter.

\section{MARIUS MYRSTAD}

Seksjon for geriatri, slag og rehabilitering

Medisinsk avdeling

og

Forskningsavdelingen

Bærum sykehus

Han har bidratt med prosjektplanlegging, datainnsamling (Bærum sykehus), utarbeiding av manus og har godkjent den siste manusversjonen.

Marius Myrstad er ph.d., spesialist i geriatri og postdoktor.

Forfatter har fylt ut ICMJE-skjemaet og oppgir ingen interessekonflikter. 
Medisinsk avdeling

Sykehuset Levanger

Han har bidratt med datainnsamling (Sykehuset Levanger), utarbeiding av manus og har godkjent

den siste manusversjonen.

Christian Myrstad er spesialist i geriatri og overlege.

Forfatter har fylt ut ICMJE-skjemaet og oppgir ingen interessekonflikter.

\section{MARTE MELLINGSAETER}

Avdeling for geriatri

Akershus universitetssykehus

Hun har bidratt med datainnsamling (Akershus universitetssykehus), utarbeiding av manus og har godkjent den siste manusversjonen.

Marte Mellingsæter er ph.d. og seksjonsleder.

Forfatter har fylt ut ICMJE-skjemaet og oppgir ingen interessekonflikter.

\section{MARTE SOFIE WANG-HANSEN}

Sykehuset i Vestfold, Tønsberg

og

Institutt for klinisk medisin

Universitetet i Oslo

Hun har bidratt med datainnsamling (Sykehuset Vestfold), utarbeiding av manus og har godkjent den siste manusversjonen.

Marte Sofie Wang-Hansen er spesialist i geriatri, seksjonsoverlege og stipendiat.

Forfatter har fylt ut ICMJE-skjemaet og oppgir ingen interessekonflikter.

\section{BJ ØRN ERIK NEERLAND}

Geriatrisk avdeling

Oslo universitetssykehus

Han har bidratt med prosjektplanlegging, datainnsamling (Oslo universitetssykehus), utarbeiding av manuset og har godkjent den siste manusversjonen.

Bjørn Erik Neerland er ph.d., spesialist i geriatri, overlege og postdoktor.

Forfatter har fylt ut ICMJE-skjemaet og oppgir ingen interessekonflikter.

\section{BAKGRUNN}

Delirium er vanlig og underdiagnostisert blant pasienter på sykehus og er assosiert med komplikasjoner, økt dødelighet, demensutvikling og behov for sykehjemsplass. Kognitiv svikt av andre årsaker er også vanlig blant sykehusinnlagte eldre og er en viktig risikofaktor for delirium. Da det ikke er gjort kartlegging av tilstandene i norske sykehus, undersøkte vi forekomsten av delirium og kognitiv svikt blant eldre pasienter i norske akuttmottak på World Delirium Awareness Day 14.3.2018.

\section{MATERIALE OG METODE}

Vi inkluderte pasienter $\geq 75$ år som ankom ti norske akuttmottak mellom kl 8 og 22 denne dagen. Vi undersøkte delirium og kognitiv svikt ved hjelp av screeningverktøyet "4AT» og registrerte alder, kjønn, innleggelsessykehus og innleggelsesavdeling (indremedisin, kirurgi, ortopedi, «andre»).

\section{RESULTATER}

Av 118 inkluderte pasienter hadde $20(17 \%)$ tegn til delirium og $36(30 \%)$ tegn til annen kognitiv svikt. Alle sykehus og alle kategorier avdelinger mottok pasienter med slike tegn.

\section{FORTOLKNING}

Både delirium og andre former for kognitiv svikt er vanlig blant eldre pasienter i norske akuttmottak. Våre tall tyder på at alle sykehusavdelinger som behandler eldre pasienter regelmessig ser disse problemstillingene. Alle avdelinger bør derfor ha rutiner for å identifisere og håndtere pasienter med delirium og kognitiv svikt. 
Delirium er en akutt endring i oppmerksomhet, bevissthet og kognisjon som oppstår i forbindelse med fysiologiske endringer som sykdom, skader eller kirurgi (ramme 1) (1). Delirium kan ramme alle, men høy alder og kognitiv svikt øker risikoen betydelig (2). Prognosen ved delirium er alvorlig, med høy dødelighet, $ø$ kt behov for sykehjemsplass og $\emptyset \mathrm{kt} \mathrm{risiko} \mathrm{for} \mathrm{utvikling} \mathrm{av} \mathrm{demens} \mathrm{(3).} \mathrm{Pasienter} \mathrm{med} \mathrm{delirium} \mathrm{har} \mathrm{også} \mathrm{høyere} \mathrm{risiko} \mathrm{for}$ sykehuskomplikasjoner, og delirium bidrar til forlenget liggetid og økte kostnader $(2,4)$. Tilstanden kan være krevende å håndtere for helsepersonell (5) og er en skremmende erfaring for pasienter (6) og pårørende (7).

\section{Ramme 1 DSM-5 - Diagnostiske kriterier for delirium}

1. En forstyrrelse i oppmerksomhet (redusert evne til å rette, fokusere, opprettholde og flytte oppmerksomhet) og bevissthet (redusert orientering om miljøet omkring).

2. Forstyrrelsen utvikles i løpet av kort tid (vanligvis timer til noen få dager), er en endring fra personens vanlige oppmerksomhet og bevissthet, og har tendens til å fluktuere i alvorlighetsgrad gjennom døgnet.

3. I tillegg ses en forstyrrelse i kognisjon (f.eks. forstyrret hukommelse, orientering, språk, visuospatial evne eller persepsjon).

4. Forstyrrelsene i kriteriene $\mathrm{A}$ og $\mathrm{C}$ blir ikke bedre forklart av en annen nevrokognitiv lidelse som allerede er etablert eller som er under utvikling, og de forekommer ikke i sammenheng med en alvorlig bevissthetsnedsettelse som f.eks. koma.

5. Det er holdepunkter fra sykehistorie, klinisk undersøkelse eller laboratorieundersøkelser for at forstyrrelsen er en direkte fysiologisk konsekvens av en annen medisinsk tilstand, forgiftning eller abstinens (f.eks. av rusmidler eller legemidler), annen toksisk påvirkning eller har flere slike årsaker.

Da delirium er en alvorlig tilstand som per definisjon har en somatisk årsak, er det avgjørende at deliriet blir erkjent og at behandlingen rettes mot å korrigere alle reversible årsaker (2). Internasjonale studier tyder på at en av ti eldre pasienter i akuttmottak har delirium (8-11). I medisinske avdelinger har en av tre eldre pasienter delirium (2), og nær halvparten av pasienter med hoftebrudd utvikler delirium i forløpet (12). Også blant intensivpasienter og hos pasienter i livets sluttfase er tilstanden svært vanlig (13, 14). Da delirium er både vanlig og alvorlig, er det uheldig at tilstanden overses i over $60 \%$ av tilfellene $(15,16)$.

Svikt i kognitive funksjoner er et viktig symptom ved delirium, men kognitiv svikt ses også ved demens og ikke sjelden ved depresjon, noe som kan gjøre differensialdiagnostikk vanskelig. Slik underliggende kognitiv svikt er også en viktig risikofaktor for delirium. Da delirium har alvorlig prognose (3) og pasienter med kognitiv svikt er mer utsatt for komplikasjoner ved sykehusopphold enn andre pasienter (17), er det viktig å oppdage både delirium og annen kognitiv svikt så tidlig som mulig under sykehusoppholdet, slik at målrettet behandling og effektive miljøtiltak kan iverksettes (18). Per i dag kartlegges og dokumenteres verken symptomer på delirium eller kognitiv svikt rutinemessig ved norske sykehus (19).

De siste årene har deliriumforskere verden over markert World Delirium Awareness Day (WDAD) for å øke kunnskapen om delirium blant helsepersonell og legfolk (20). Inspirert av italienske og britiske punktprevalensundersøkelser om delirium $(21,22)$ tok vi initiativ til en tilsvarende undersøkelse på deliriumdagen i 2018. Hensikten var å kartlegge 
forekomsten av primært delirium, sekundært andre former for kognitiv svikt. Vi gjorde unders $\varnothing$ kelsen i akuttmottakene, da forekomsten av disse tilstandene ikke er kartlagt der og fordi akuttmottakene mottar et bredt spekter av pasienter. Klinikere ved flere avdelinger kan dermed relatere seg til våre funn.

\section{Materiale og metode}

Vi gjennomførte en punktprevalensundersøkelse om delirium og kognitiv svikt hos pasienter $\geq 75$ år som ankom norske akuttmottak i tidsrommet kl 8-22 14. mars 2018. En geriater eller en lege med lang erfaring i geriatri vurderte pasienten for delirium og kognitiv svikt ved hjelp av det validerte screeningverktøyet 4AT (se appendiks) og registrerte alder, kjønn, klokkeslett og innleggelsesavdeling (indremedisin, kirurgi, ortopedi og «andre»). Totalt deltok 13 leger fordelt på Helgelandssykehuset Mo i Rana, Sykehuset Levanger, St. Olavs hospital, Førde sentralsjukehus, Sykehuset i Vestfold, Kongsberg sykehus, Bærum sykehus, Diakonhjemmet Sykehus, Oslo universitetssykehus, Ullevål og Akershus Universitetssykehus.

\section{DIAGNOSTIKK}

4AT er utviklet i Storbritannia og oversatt til flere språk, deriblant norsk $(23,24)$. Testen består av fire punkter, og pasienten kan få o-12 poeng. En skår på 4 eller mer skal vekke mistanke om delirium, skår 1-3 skal vekke mistanke om kognitiv svikt uten pågående delirium, mens en skår på o gjør kognitiv svikt og delirium lite sannsynlig (24). 4AT er et validert screeningverktøy for delirium med sensitivitet $87-93 \%$ og spesifisitet $70-91 \%(15,16$, 23).

I første punkt skal undersøkeren vurdere om pasienten er normalt årvåken og oppmerksom på omgivelsene. Normal årvåkenhet gir o poeng, alt annet gir 4 poeng. Punkt 2 er en kort orienteringstest der pasienten skal oppgi egen alder, fødselsdato, sted for undersøkelsen og årstall. Avhengig av svar får pasienten o, 1 eller 2 poeng. Punkt 3 er en oppmerksomhetstest der pasienten skal si årets måneder i motsatt rekkefølge (desember-november-oktober osv.). Å klare syv måneder gir o poeng, færre enn syv måneder 1 poeng, mens pasienter som ikke er testbare eller ikke kommer i gang med testen, får 2 poeng. I punkt 4 skal undersøkeren ut fra sykehistorie, komparentopplysninger og journalopplysninger vurdere om det er holdepunkter for akutte endringer eller fluktuasjon i kognisjon, oppmerksomhet eller bevissthet. Dersom dette er tilfellet, får pasienten 4 poeng.

\section{ETIKK}

Aktuelle pasienter ble forespurt om deltagelse og mottok et informasjonsskriv om studiens innhold og hensikt. Pasienter som virket å forstå innholdet i studien og sa seg villig til å delta, samtykket selv til deltagelse med underskrift. Dersom legen vurderte at pasienten ikke var samtykkekompetent, innhentet vedkommende samtykke fra ledsagende pårørende. Pasienter uten samtykkekompetanse og uten pårørende ble ikke inkludert. Prosjektet ble godkjent av Regional etisk komité Nord (2017/2420).

\section{STATISTIKK}

Vi presenterer dikotome og nominelle data som hele tall, og prosentandeler og kontinuerlige data som gjennomsnitt og standardavvik. Vi gjorde deskriptiv statistikk med SPSS versjon 25 og utarbeidet figurer i Excel versjon 2016.

\section{Resultater}

Totalt 140 pasienter $\geq 75$ år ankom akuttmottakene på de ti aktuelle sykehusene $\mathrm{i}$ tidsrommet mellom kl 8 og 22 14.3.2018. Av disse ble 118 pasienter ( $84 \%$ ) inkludert i prosjektet. Ti pasienter ønsket ikke å delta, fire pasienter var ikke i stand til å gi samtykke. Fire pasienter ble ikke spurt om deltagelse, og fire pasienter kunne av ulike grunner ikke delta i studien. Gjennomsnittsalderen var 83,5 år (standardavvik 6,1) og 63 (53\%) var kvinner. 
Majoriteten ble innlagt på indremedisinske avdelinger (63\%), mens henholdsvis $15 \%, 13 \%$ og $9 \%$ ble innlagt på kirurgiske, ortopediske og andre avdelinger.

20 av 118 pasienter (17\%) hadde delirium vurdert ved 4AT. Vi fant tegn til kognitiv svikt hos ytterligere 36 pasienter, slik at totalt 56 pasienter $(47 \%)$ hadde tegn til en eller annen form for kognitiv svikt. Åtte av ti sykehus mottok pasienter med delirium, og alle sykehus mottok pasienter med tegn til kognitiv svikt. Figur 1 viser at pasienter med delirium og/eller kognitiv svikt utgjorde en stor andel av de eldre pasientene både på medisinske, kirurgiske, ortopediske og de resterende typer avdelinger denne dagen.

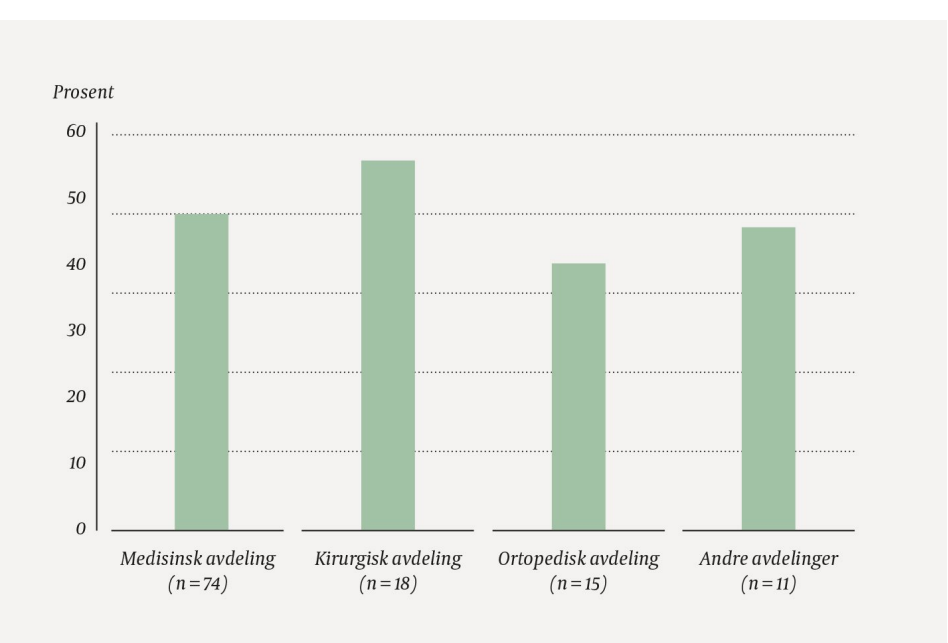

Figur 1 Andel pasienter innlagt på ulike typer avdelinger med tegn til delirium og/eller andre former for kognitiv svikt.

\section{Diskusjon}

I denne punktprevalensundersøkelsen blant pasienter $\geq 75$ år i ti norske akuttmottak hadde $17 \%$ funn forenlig med delirium og ytterligere $30 \%$ funn forenlig med kognitiv svikt av annen årsak vurdert med screeningverktøyet 4 AT. Alle kategorier avdelinger mottok pasienter med delirium. Alle deltagende sykehus mottok pasienter med tegn til delirium eller annen kognitiv svikt.

Forekomsten av delirium var noe høyere enn i tilsvarende studier fra andre land, der man har funnet en forekomst på rundt $10 \% \mathrm{i}$ akuttmottak (8-11). En sannsynlig årsak er at vi inkluderte pasienter $\geq 75$ år, mens de øvrige studiene satte nedre inklusjonsgrense til 65 år. Norske akuttmottak har også mer selekterte pasienter enn akuttmottak i mange andre land som også tar imot pasienter som henvender seg direkte, slik som på våre legevakter. Den totale forekomsten av kognitiv svikt på $47 \%$ er omtrent som i andre studier som har funnet kognitiv svikt hos om lag halvparten av eldre pasienter i akuttmottak $(25,26)$.

Pasienter med kognitiv svikt har høy risiko for å utvikle delirium og å pådra seg andre komplikasjoner under sykehusoppholdet (17). Da delirium er assosiert med dårlig prognose (3), komplikasjoner, økt liggetid og økte kostnader, (4) er det avgjørende at sykehusene har fokus på forebygging og god håndtering av delirium. I en metaanalyse konkluderer man med at nær halvparten av alle tilfeller av delirium kan forebygges med enkle, men personellkrevende tiltak som orientering, fokus på drikke og ernæring, aktivisering, mobilisering og god søvnhygiene (18). Slike tiltak har også dokumentert effekt ved etablert delirium, i motsetning til psykofarmaka som frarådes brukt rutinemessig både for å forebygge og behandle delirium (2). Vi frykter imidlertid at forhold som overbelegg, korridorpasienter, kort liggetid og lav bemanning bidrar til økt forekomst og dårligere behandling av delirium.

Ettersom delirium er svært vanlig, er assosiert med en lang rekke negative utfall og i stor grad kan forebygges, mener vi at bedre forebygging og håndtering av delirium vil ha stor positiv betydning for pasientsikkerheten ved norske sykehus. Vi etterlyser en offensiv holdning til delirium og kognitiv svikt og mener det er naturlig å inkludere disse 
tilstandene som fokusområde i pasientsikkerhetsprogrammet (27). Våre tall illustrerer at pasienter med både delirium og annen kognitiv svikt legges inn på de fleste typer avdelinger, noe som underbygger at konkrete planer for håndtering av pasienter med delirium og kognitiv svikt bør foreligge på alle avdelinger som behandler eldre pasienter, og ikke bare være et anliggende for geriatriske avdelinger.

Vi anbefaler også å innføre rutiner for undersøkelse av delirium og kognitiv status i akuttmottak $(4,25,26)$. Dette vil føre til at flere tilfeller av delirium blir erkjent, og siden delirium er et tegn på sykdom, vil dette antagelig medføre grundigere diagnostikk og bedre behandling. Erkjennelse av delirium vil også redusere risikoen for at tilstanden feilaktig blir oppfattet som demens. Tidlig identifisering av pasienter med kognitiv svikt vil medføre at man kan gi tilpasset informasjon, starte målrettede forebyggende tiltak mot delirium og andre komplikasjoner $(17,18)$ og bedre utreiseplanleggingen for disse pasientene. Erkjennelse av delirium kan også identifisere pasienter med behov for tettere oppfølging etter utreise. Da delirium er underdiagnostisert $(15,16)$, anbefaler vi bruk av et standardisert screeningverktøy. 4AT kan gi en meningsfull skår også for pasienter som ikke kan svare på spørsmål, og verktøyet gir en pekepinn på om pasienter uten delirium kan ha underliggende kognitiv svikt.

\section{STYRKER OG BEGRENSNINGER}

De viktigste styrkene ved denne studien er at kartleggingen er gjort ved hjelp av et validert screeningverktøy for delirium og er gjennomført på ti ulike sykehus av leger med lang erfaring med eldre pasienter. Likevel er materialet relativt lite og begrenset til den aktuelle datoen. Vi understreker at 4AT er et screeningverktøy og derfor ikke må brukes som grunnlag for endelige diagnoser som demens eller mild kognitiv svikt. Andre begrensninger er at vi ikke har registrert risikofaktorer for delirium som skrøpelighet, multisykdom, polyfarmasi eller kjent kognitiv svikt.

\section{Konklusjon}

På Deliriumdagen 14.3.2018 hadde $17 \%$ av pasientene $\geq 75$ år som var henvist til et utvalg av norske akuttmottak tegn til delirium, og ytterligere $30 \%$ hadde tegn til andre former for kognitiv svikt. Alle sykehus og alle kategorier avdelinger mottok pasienter med tegn til delirium og/eller kognitiv svikt, noe som underbygger at alle avdelinger som behandler eldre pasienter bør ha rutiner og kompetanse for å ivareta pasienter med delirium og kognitiv svikt på en best mulig måte.

\section{HOVEDBUDSKAP}

På Deliriumdagen 14.3.2018 undersøkte vi 118 pasienter $\geq 75$ år i ti norske akuttmottak med tanke på delirium og andre former for kognitiv svikt $17 \%$ hadde tegn til delirium og $30 \%$ hadde tegn til andre former for kognitiv svikt

Alle typer avdelinger og alle sykehus mottok pasienter med symptomer på delirium og/eller kognitiv svikt på undersøkelsestidspunktet

\section{LITTERATUR:}

1. American Psychiatric Association. Diagnostic and Statistical Manual of Mental Disorders (DSM-5). Washington DC: American Psychiatric Publishing, 2013.

2. Marcantonio ER. Delirium in hospitalized older adults. N Engl J Med 2017;377: 1456-66.

[PubMed][CrossRef]

3. Witlox J, Eurelings LS, de Jonghe JF et al. Delirium in elderly patients and the risk of postdischarge mortality, institutionalization, and dementia: a meta-analysis. JAMA 2010; 304: 443-51. 
4. Inouye SK, Westendorp RG, Saczynski JS. Delirium in elderly people. Lancet 2014;383: 911-22. [PubMed][CrossRef]

5. Meagher DJ, Leonard M, Donnelly S et al. A longitudinal study of motor subtypes in delirium: relationship with other phenomenology, etiology, medication exposure and prognosis. J Psychosom Res 2011; 71:395-403. [PubMed][CrossRef]

6. Instenes I, Gjengedal E, Eide LSP et al. “Eight days of nightmares ... ” - Octogenarian patients' experiences of postoperative delirium after transcatheter or surgical aortic valve replacement. Heart Lung Circ 2018; 27: 260-6. [PubMed][CrossRef]

7. Morandi A, Lucchi E, Turco R et al. Delirium superimposed on dementia: A quantitative and qualitative evaluation of informal caregivers and health care staff experience. J Psychosom Res 2015; 79: 272-8o. [PubMed][CrossRef]

8. Elsayem AF, Bruera E, Valentine AD et al. Delirium frequency among advanced cancer patients presenting to an emergency department: A prospective, randomized, observational study. Cancer 2016; 122: 2918-24. [PubMed][CrossRef]

9. Émond M, Boucher V, Carmichael PH et al. Incidence of delirium in the Canadian emergency department and its consequences on hospital length of stay: a prospective observational multicentre cohort study. BMJ Open 2018; 8: eo1819o. [PubMed][CrossRef]

10. Kennedy M, Enander RA, Tadiri SP et al. Delirium risk prediction, healthcare use and mortality of elderly adults in the emergency department. J Am Geriatr Soc 2014; 62: 462-9. [PubMed][CrossRef]

11. Sri-on J, Tirrell GP, Vanichkulbodee A et al. The prevalence, risk factors and short-term outcomes of delirium in Thai elderly emergency department patients. Emerg Med J 2016; 33: 17-22.

[PubMed][CrossRef]

12. Juliebø V, Bjøro K, Krogseth M et al. Risk factors for preoperative and postoperative delirium in elderly patients with hip fracture. J Am Geriatr Soc 2009; 57: 1354-61. [PubMed][CrossRef]

13. Ely EW, Shintani A, Truman B et al. Delirium as a predictor of mortality in mechanically ventilated patients in the intensive care unit. JAMA 2004; 291: 1753-62. [PubMed][CrossRef]

14. Hosker CM, Bennett MI. Delirium and agitation at the end of life. BMJ 2016; 353: i3085.

[PubMed][CrossRef]

15. O'Sullivan D, Brady N, Manning E et al. Validation of the 6-Item Cognitive Impairment Test and the $4 \mathrm{AT}$ test for combined delirium and dementia screening in older Emergency Department attendees. Age Ageing 2018; 47: 61-8. [PubMed][CrossRef]

16. Hendry K, Quinn TJ, Evans J et al. Evaluation of delirium screening tools in geriatric medical inpatients: a diagnostic test accuracy study. Age Ageing 2016; 45: 832-7. [PubMed][CrossRef]

17. Bail K, Berry H, Grealish L et al. Potentially preventable complications of urinary tract infections, pressure areas, pneumonia, and delirium in hospitalised dementia patients: retrospective cohort study. BMJ Open 2013; 3: eoo2770. [PubMed][CrossRef]

18. Hshieh TT, Yue J, Oh E et al. Effectiveness of multicomponent nonpharmacological delirium interventions: a meta-analysis. JAMA Intern Med 2015; 175: 512-20. [PubMed][CrossRef]

19. Watne LO, Wyller TB. Delirium - framleis underdiagnostisert. Tidsskr Nor Legeforen 2018; 138. doi: 10.4045/tidsskr.18.0118. [PubMed][CrossRef]

20. iDelirium. The International Federation of Delirium Societes. www.idelirium.org (13.12.2018).

21. Bellelli G, Morandi A, Di Santo SG et al. “Delirium Day”: a nationwide point prevalence study of delirium in older hospitalized patients using an easy standardized diagnostic tool. BMC Med 2016; 14: 106. [PubMed][CrossRef]

22. Ryan DJ, O’Regan NA, Caoimh RÓ et al. Delirium in an adult acute hospital population: predictors, prevalence and detection. BMJ Open 2013; 3: eoo1772. [PubMed][CrossRef]

23. Bellelli G, Morandi A, Davis DH et al. Validation of the 4 AT, a new instrument for rapid delirium screening: a study in 234 hospitalised older people. Age Ageing 2014; 43: 496-502. [PubMed][CrossRef] 24. Evensen S, Forr T, Al-Fattal A et al. Nytt verktøy for å oppdage delirium og kognitiv svikt. Tidsskr 
Nor Legeforen 2016; 136: 299-30o. [PubMed][CrossRef]

25. Pendlebury ST, Klaus SP, Mather M et al. Routine cognitive screening in older patients admitted to acute medicine: abbreviated mental test score (AMTS) and subjective memory complaint versus Montreal Cognitive Assessment and IQCODE. Age Ageing 2015; 44: 1000-5. [PubMed][CrossRef]

26. Reynish EL, Hapca SM, De Souza N et al. Epidemiology and outcomes of people with dementia, delirium, and unspecified cognitive impairment in the general hospital: prospective cohort study of 10,014 admissions. BMC Med 2017; 15: 140. [PubMed][CrossRef]

27. I trygge hender. https://www.pasientsikkerhetsprogrammet.no (13.12.2018).

Publisert: 13. mars 2019. Tidsskr Nor Legeforen. DOI: 10.4045/tidsskr.18.0578

Mottatt 13.7.2018, første revisjon innsendt 14.12.2018, godkjent 23.1.2019.

(C) Tidsskrift for Den norske legeforening 2020. Lastet ned fra tidsskriftet.no 